\title{
Giant Corneal Keloid: Case Report and Review of the Literature
}

\author{
Jesse J. Jung, MD1, Ted H. Wojno, MD¹, and Hans E. Grossniklaus, MD1,2 \\ ${ }^{1}$ Department of Ophthalmology, Emory University School of Medicine, Atlanta, Georgia \\ ${ }^{2}$ Department of Pathology, Emory University, School of Medicine, Atlanta, Georgia
}

\begin{abstract}
Purpose-To report a patient with a tumor-like corneal keloid.

Methods-Retrospective review of clinical features and histopathologic findings.

Results-A 68-year-old woman with a remote history of an orbital tumor treated with radiation developed a corneal tumor. A biopsy of the tumor showed fibrocellular tissue and her blind, painful eye was enucleated. Pathologic findings in the enucleated eye showed that the corneal mass was consistent with a large keloid.
\end{abstract}

Conclusions-A corneal keloid may clinically appear as a large corneal tumor.

Corneal keloid, first described in $1865^{1}$, is a rare condition consisting of a proliferation of benign fibrovascular tissue. There have been approximately 76 documented cases of corneal keloid previously reported. ${ }^{1-26}$ Most reported cases have occurred secondary to penetrating injury or surgery and it is thought that inflammation causes a fibroblastic reaction resulting in the keloid. ${ }^{24,27}$

Herein, we report a case of corneal keloid that developed in a patient with no history of ocular surgery or trauma. There have been other instances where corneal keloid formed in patients without prior corneal injury. Our patient had a remote history of radiation therapy for an orbital tumor and a tarsorraphy, which may have contributed to the keloid formation.

\section{Case Report}

A 68-year-old African American woman was evaluated in July, 20007 for an enlarging growth and bloody discharge from her right eye. The lesion had been present for two years and had progressively enlarged. She had no history of trauma or ocular surgery. In 1991, she related that she had been treated with radiation therapy for an orbital tumor and a tarsorraphy, although further details about that treatment were unavailable. A previous biopsy of the orbital mass showed fibro-inflammatory tissue. She had no history of inflammatory eye disease and her medical history was otherwise unremarkable.

On initial presentation, she had no light perception vision in her right eye and the best corrected vision in her left eye was 20/25. Abnormal findings were confined to her right eye. External examination showed a smooth, white to tan, raised corneal mass covering the entire

Address correspondence to: Hans E. Grossniklaus MD, L.F. Montgomery Ophthalmic Pathology Laboratory, BT 428, 1365 Clifton Road, Altanta, Georgia 30322, fax 404-778-4610, ophtheg@emory.edu.

Publisher's Disclaimer: This is a PDF file of an unedited manuscript that has been accepted for publication. As a service to our customers we are providing this early version of the manuscript. The manuscript will undergo copyediting, typesetting, and review of the resulting proof before it is published in its final citable form. Please note that during the production process errors may be discovered which could affect the content, and all legal disclaimers that apply to the journal pertain. 
corneal surface (Fig 1). She also had evidence of a tarsorraphy. Applanation tonometry, anterior segment examation, and dilated fundus examination were precluded by the corneal mass. Magnetic resonance imaging (MRI) of the right orbit showed a $3 \times 1 \mathrm{~cm}$ soft tissue mass aroud the optic nerve in the central and lateral superior aspect of the orbit. A biopsy of the corneal lesion showed non-specific fibrocellular tissue. The patient underwent enucleation of her blind, painful right eye. Gross examination of the enucleated eye showed a $9 \times 8 \times 3 \mathrm{~mm}$ corneal mass (Fig 2). The lens was opaque and the vitreous was collapsed. The retina was atrophic. Microscopic examination showed that the corneal mass was located between the epithelium and Bowman's layer. (Fig 3) The mass was composed of bland, spindle-shaped cells enmeshed in a loosely cohesive collagenous matrix with interspersed vascular channels. Portions of the mass were heavily collagenized, vascularized, and contained pigmented and non-pigmented cells while other portions were more loosely cohesive (Fig 4). Bowman's layer was disrputed underlying the mass. The corneal stroma was edematous and scarred. There was neovascularizaiton of the iris, peripheral anterior synechiae, cataractous changes in the lens, and glaucomatous atrophy of the retina and optic nerve. A trichrome stain highlighted the collagen bundles in the corneal mass and immunohistochemical stains were positive for smooth muscle actin in cells in the mass (Fig 5). The corneal mass was classified as a keloid. The post-operative course was uneventful.

\section{Discussion}

Corneal keloid may present at any age, although they most commonly present in the first two decades of life. ${ }^{19,23}$ The clinical differential diagnosis includes sclerocornea, dermoid, myxoma, Salzmann's nodular degeneration, Peter's anomaly, congenital hereditary endothelial dystrophy, congenital glaucoma, familial band-shaped keratopahy, spheroidal degeneration, squamous cell carcinoma, juvenile xantogranuloma, fibrous histiocytoma, birth trauma, infection and metabolic disease..$^{8,10,13,15,19}$ Persons of African or Asian heritage are more susceptible than Caucasions for developing cutaneous keloid ${ }^{7}$, although it is unknown if this holds true for corneal keloid. However, Lahav and co-workers reported nine cases of corneal keloid in 45 eyes of young, African patients and noted that the keloids often occurred after untreated penetrating corneal injury. ${ }^{7}$

Corneal keloid clinically appears as a solitary, gray-white, firm, elevated, smooth, shiny nodule that is well-demarctaed from adjacent tissue, although it may involve the entire corneal stroma. ${ }^{10,17,24}$ There is often a clinical history of penetrating or non-penetrating injury preceding the development of the keloid. Corneal thickening is caused by fibrovascular hyperplasia secondary to scar formation. The lesion often covers a large area of the corneal surface, well beyond the presumed localized sit of injury. 2,11,17,24,26. Ultrasound evaluation of corneal keloid usually shows a solid lesion with high echogenecity $1^{13}$, a thickened cornea, poorly defined angle anatomy and possible iridocorneal touch. ${ }^{10}$ Anterior chamber and lens structures are usually normal unless there is an associated heritable syndrome. ${ }^{11}$ If the keloid arises secondary to penetrating trauma, iris incarceration into the wound may also be present. ${ }^{19}$

The diagnosis of most cases of corneal keloid has been made by pathologic examination rather than clinical examination. ${ }^{11,17}$ The thickened epithelium may exhibit hyperplasia, keratinization, parakeratosis and basilar edema. Bowman's layer is usually disrupted or absent. ${ }^{26}$ The stroma may contain irregularly arranged fibroblasts, collagen bundles, and vascular channels $7,10,15,16,19,23$ along with activated fibroblasts, myofibroblasts and hyalized collage in later stages. ${ }^{7,24,26}$ Neovascularization may be located anteriorly or diffusely throughout the stroma with the origin of the vessels from either the peripheral cornea or incarcerated iris. ${ }^{17,24}$ The keloid from our patient had many of these findings, including hyperplastic epithelium overlying edematous, heavily collagenized fibrovascular 
tissue. The underlying Bowman's layer was disrupted and activated fibroblasts along with vascular channels were present within the keloid.

The histogenesis of keloid may be divided into an early inflammatory stage followed by fibroblastic, fibrous and hyaline stages. Initially, there is increased vascualrity, hyperplasia of juvenile fibroblasts, and production of collage type III fibrils during the inflammatory and fibroblastic stages. During the fibrous stage, collage type I becomes tightly packed and there is a reduction in both vascularity and juvenile fibroblasts. Compact collagen stroma then fuses and becomes homogenous to form the the final hyaline stage. ${ }^{7,24,26}$ It is believed that in keloids, myofibroblasts which are transformed fibroblasts that express smooth muscle phenotypes persist and often dominate the cell population. Eventually they deposit material that slowly collagenizes int eh center but does not retract. This produces a bulky slow

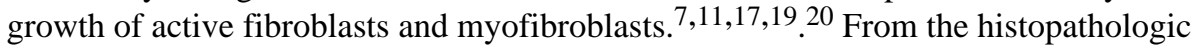
findings of the diffuse fibrovascular tissue, vascular channels, heavy collagenization, and limited amounts of hyaline tissue in our patient, the keloid was in the late fibroblastic or fibrous stage of development.

Based on cases of perforating injury, some have suggested that corneal keloids originate from stromal cells of the iris incarcerated into the corneal site thus inducing proliferation. In those instances, blood vessels within the keloid originate from iris tissue. ${ }^{5,18}$ Others have suggested that excessive proliferation of fibrovascular connective tissue occurs during the healing phase of an inflammatory reaction or perforating injury and does not necessarily result from the iris incarceration. ${ }^{18,19}$ Although iris incarceration is a possible explanation, there are corneal keloids that form after penetrating trauma where no iris cells are present within the proliferating fibrovascular tissue. ${ }^{3} \mathrm{O}$ 'Grady and co-workers reviewed foru cases and found that keloid formation was from relatively normal peripheral cornea and only one traumatic case had iris pigment present in the keloid. ${ }^{3}$ There have also been two cases of non-penetrating injury where a corneal keloid developed without evidence of perforation or iris involvement. ${ }^{17,24}$ Based on O'Grady's report and these other cases, it is likely that corneal stromal overgrowth during the reparative phase of corneal healing in response to an inflammatory process or injury may lead to keloid development. ${ }^{6,7,16,23}$ Our patient had a history of radiation and a tarsorraphy for exposure keratopathy and the esposure keratopathy was the likely cause of the keloid formation.

Corneal keloids are also common with certain genetic syndrome. Lowe's syndrome, an Xlinked recessive disorder characterized by hydrophthalmia, cataracts, intellectual disabilities, aminoaciduria, and vitamin D-resistance rickets, has been associated with congenital corneal keloids. ${ }^{14,18,22,28}$ It is believed that in Lowe's syndrome, increased levels of amino acids such as tyrosine leaking from abnormal new corneal vessels or from within the anterior chamber through defective endothelium stimulate fibroblast proliferation. $14,20,22$ Another genetic syndrome associated with corneal keloids is Rubinstein-Taybi syndrome(RTS). Rao and co-workers reported bilateral corneal keloids along with the RTS constellation of symptoms of broad thumbs and great toes, short stature, mental retardation, congenital heart defects, and characteristic faces. ${ }^{10}$ Besides these two genetic syndromes, authors have reported that congenital corneal keloids are associated with ocular anomalies such as peripheral iridocorneal adhesions, subluxated lenses 21 ; aniridia and cataract with anopthalmia.15 In those idiopathic cases, it is postulated that there was a failure of normal corneal tissue differentiation during embryogenesis resulting in the occurrence of keloids and concomitant failure of the development of normal ocular tissue.15,20,21 Congenital and genetic syndrome keloids appear to be a result of anterior-segment mesenchymal dysgenesis. 
There have been three cases of corneal keloids in patients who did not have congenital corneal keloids, had no prior history of ocular injury or trauma, no prior history of chronic inflammation and no family history of fibrovascular proliferative disease. Holbach and coworkers reported two cases of bilateral corneal keloids in two 6-month-old boys and hypothesized that unrecognized corneal infection could introduce microbial antigens, which created an immune-mediated reaction resulting in a hypertrophic keloid [8]. Mejia and coworkers reported on a 17-year-old case and proposed fibrovascular overgrowth was due to effects of cytokines released by injured epithelium affecting the normal corneal response to injury. ${ }^{26}$ This explanation was supported by Dhooge and co-workers reported a child with Fibrodyplasia Ossificans Progressiva (FOP) who developed a unilateral keloid after pterygium repair. They hypothesized that high levels of BMP4 in FOP inhibited the normal signaling of TGF- $\beta$ and activin, therefore overstimulating fibroblastic growth in corneal wound healing. 2 Cytokines such as basic fibroblast growth factor can have an inhibitory affect on the function of TGF- $\beta$, a paracrine and autocrine hormone, involved with the normal differentiation of cornea stroma and wound contraction.26,27 Basic fibroblast growth factor has been shown to induce profound keratocyte proliferation and wound neovascularization.27 Shoukrey and co-workers showed that basal epithelial cells can transform into myofibroblasts and develop contractile elements ${ }^{24}$ and cytokines may promote unregulated fibrovascular growth into a corneal keloid.

In our case, there was apparent radiation damage to intraocular structures such as the iris, lens, and retina. On histopathological exam, the iris leaflets exhibited neovascularization. The iris was also adherent to the posterior surface of the cornea. Within the posterior corneal stroma, there was diffuse vascularization most likely from the long-standing corneal disease. We believe that the chronic inflammation from the iris tissue and possibly leakage of amino acids from the neovascularization within the posterior stroma could have created the persistent inflammatory state that triggered fibrovascular growth. Inflammatory cytokines such as basic fibroblastic growth factor and interferons could have been released from the blood vessels and injured epithelial cells creating the ongoing proliferation of fibrous tissue and vascular channels.

Successful treatment of corneal keloid has included superficial keratectomy, lamellar excision, lamellar keratoplasty or penetrating keratoplasty. Lamellar keratectomy is possible unless there is deep stromal involvement of the lesion. ${ }^{18}$ Several authors have reported success with superficial lamellar keratectomy with amniotic membrane coverage. ${ }^{11,13}$ Sclerokeratoplasty has also been performed successfully as an alternative procedure to preserve the globe when conventional keratoplasty could not be performed secondary to severe destruction of the cornea. Visual results from all the procedures are variable but anterior reconstruction of the eye is usually good. ${ }^{16}$

Although benign growths, keloids may severely affect vision resulting in cases of no light perception, and large hypertrophic scars may interfere with eyelid closure. ${ }^{18}$ These lesions may also become irritated from exposure and become extremely painful. Incomplete surgical excision of keloids can result in recurrence and enlargement of the lesions. ${ }^{18,24}$ Recurrence has been reported after superficial lamellar keratectomy $y^{8,24,25}$ and penetrating keratoplasty. ${ }^{10}$ In cases of congenital corneal keloid, penetrating keratoplasty is difficult and commonly complicated by corneal graft failure secondary to recurrent epithelial breakdown. 10,15 Enucleation is rarely performed unless the eye is nonfunctional, painful and aesthetically displeasing. 3,7

Treatment goals are directed at removing the existing lesion and preventing recurrence by inhibiting fibroblastic proliferation and collagen synthesis. In the ultrastructural analysis of corneal keloids, it was noted that the persistence of mast cells promotes recurrent 
inflammation and utilizing topical steroids or mast cell stabilizers may be useful. ${ }^{14,18}$ Other options that have been proposed include topical cyclosporine ${ }^{22}$ or the use of physical forms of treatment such as ultrasound, cryotherapy, pressure therapy and laser. ${ }^{18}$ The utilization of amniotic membrane after uperficial keratectomy has been successful in preventing recurrence and epithelial break down due to its antifibroblastic and anti-inflammotory properties. ${ }^{13}$

\section{Acknowledgments}

Supported in part by an unrestricted department grant from Research to Prevent Blindness, Inc., and NIH P30 EY06360

\section{References}

1. Smith H. Keloid of the Cornea. Transactions of the American Ophthalmological Society 1940;38:519-538. [PubMed: 16693235]

2. Dhooge MR, Idema AJ, Dhooge MRP, et al. Fibrodysplasia ossificans progressiva and corneal keloid. Cornea 2002;21(7):725-729. [PubMed: 12352096]

3. O'Grady RB, Kirk HQ. Corneal keloids. American Journal of Ophthalmology 1972;73(2):206-213. [PubMed: 5015901]

4. Frederique G, Howard RO, Boniuk V. Corneal ulcers in rubeola. American Journal of Ophthalmology 1969;68(6):996-1003. [PubMed: 5362892]

5. Farkas TG, Znajda JP. Keloid of the cornea. American Journal of Ophthalmology 1968;66(2):319323. [PubMed: 5663369]

6. Fenton RH, Tredici TJ. HYPERTROPHIC CORNEAL SCARS (KELOIDS). Survey of Ophthalmology 1964;45:561-566. [PubMed: 14232721]

7. Lahav M, Cadet JC, Chirambo M, et al. Corneal keloids--a histopathological study. Graefes Archive for Clinical \& Experimental Ophthalmology 1982;218(5):256-261.

8. Holbach LM, Font RL, Shivitz IA, et al. Bilateral keloid-like myofibroblastic proliferations of the cornea in children. Ophthalmology 1990;97(9):1188-1193. [PubMed: 2234852]

9. Finger PT, Chin KJ, Wong JJ, et al. Reactive keratoma of the central corneal epithelium. European Journal of Ophthalmology 2009;19(3):484-486. [PubMed: 19396801]

10. Rao SK, Fan DS, Pang CP, et al. Bilateral congenital corneal keloids and anterior segment mesenchymal dysgenesis in a case of Rubinstein-Taybi syndrome. Cornea 2002;21(1):126-130. [PubMed: 11805525]

11. Bourcier T, Baudrimont M, Boutboul S, et al. Corneal keloid: clinical, ultrasonographic, and ultrastructural characteristics. Journal of Cataract \& Refractive Surgery 2004;30(4):921-924. [PubMed: 15093664]

12. Gaviria JG, Johnson DA, Scribbick F 3rd, et al. Corneal keloid mimicking a recurrent limbal dermoid. Journal of Pediatric Ophthalmology \& Strabismus 2005;42(3):189-190. [PubMed: 15977875]

13. Chawla B, Agarwal A, Kashyap S, et al. Diagnosis and management of corneal keloid. Clinical \& Experimental Ophthalmology 2007;35(9):855-857. [PubMed: 18173415]

14. Cibis GW, Tripathi RC, Tripathi BJ, et al. Corneal keloid in Lowe's syndrome. Archives of Ophthalmology 1982;100(11):1795-1799. [PubMed: 7138348]

15. Weiner MJ, Albert DM. Congenital corneal keloid. Acta Ophthalmologica - Supplementum 1989;192:188-196.

16. Mendez EA, Daza MT. Sclerokeratoplasty in a case of corneal keloid. Cornea 1991;10(2):183184. [PubMed: 2019129]

17. Risco JM, Huaman A, Antonios SR. A case of corneal keloid: clinical, surgical, pathological, and ultrastructural characteristics. British Journal of Ophthalmology 1994;78(7):568-571. [PubMed: 7918270]

18. McElvanney AM, Adhikary HP. Corneal keloid: aetiology and management in Lowe's syndrome. Eye 1995;9(Pt 3):375-376. [PubMed: 7556753] 
19. Mullaney PB, Teichmann K, Huaman A, et al. Corneal keloid from unusual penetrating trauma. Journal of Pediatric Ophthalmology \& Strabismus 1995;32(5):331-334. [PubMed: 8531041]

20. Vanathi M, Sen S, Panda A, et al. Unilateral congenital corneal keloid with anterior segment mesenchymal dysgenesis and subluxated lens: case report and review of literature. Cornea 2007;26(1):111-113. [PubMed: 17198027]

21. Song JS, Kwon S, Shyn KH, et al. A case of congenital corneal keloid. Korean Journal of Ophthalmology 2005;19(2):156-159. [PubMed: 15988936]

22. Esquenazi S, Eustis HS, Bazan HE, et al. Corneal keloid in Lowe syndrome. Journal of Pediatric Ophthalmology \& Strabismus 2005;42(5):308-310. [PubMed: 16250222]

23. LeMasters WC, Notz RG. Corneal keloids. Transactions - Pennsylvania Academy of Ophthalmology \& Otolaryngology 1986;38(1):286-288. [PubMed: 3765007]

24. Shoukrey NM, Tabbara KF. Ultrastructural study of a corneal keloid. Eye 1993;7(Pt 3):379-387. [PubMed: 8224292]

25. Shukla IM, Arora NP, Arora MM. Corneal keloid. Indian Journal of Ophthalmology 1975;23(2): 18-19. [PubMed: 1236446]

26. Mejia LF, Acosta C, Santamaria JP. Clinical, surgical, and histopathologic characteristics of corneal keloid. Cornea 2001;20(4):421-424. [PubMed: 11333333]

27. Jester JV, Barry-Lane PA, Cavanagh HD, et al. Induction of alpha-smooth muscle actin expression and myofibroblast transformation in cultured corneal keratocytes. Cornea 1996;15(5):505-516. [PubMed: 8862928]

28. Lowe CU, Terrey M, Mac LE, et al. Organic-aciduria, decreased renal ammonia production, hydrophthalmos, and mental retardation; a clinical entity. A M A American Journal of Diseases of Children 1952;83(2):164-184. 


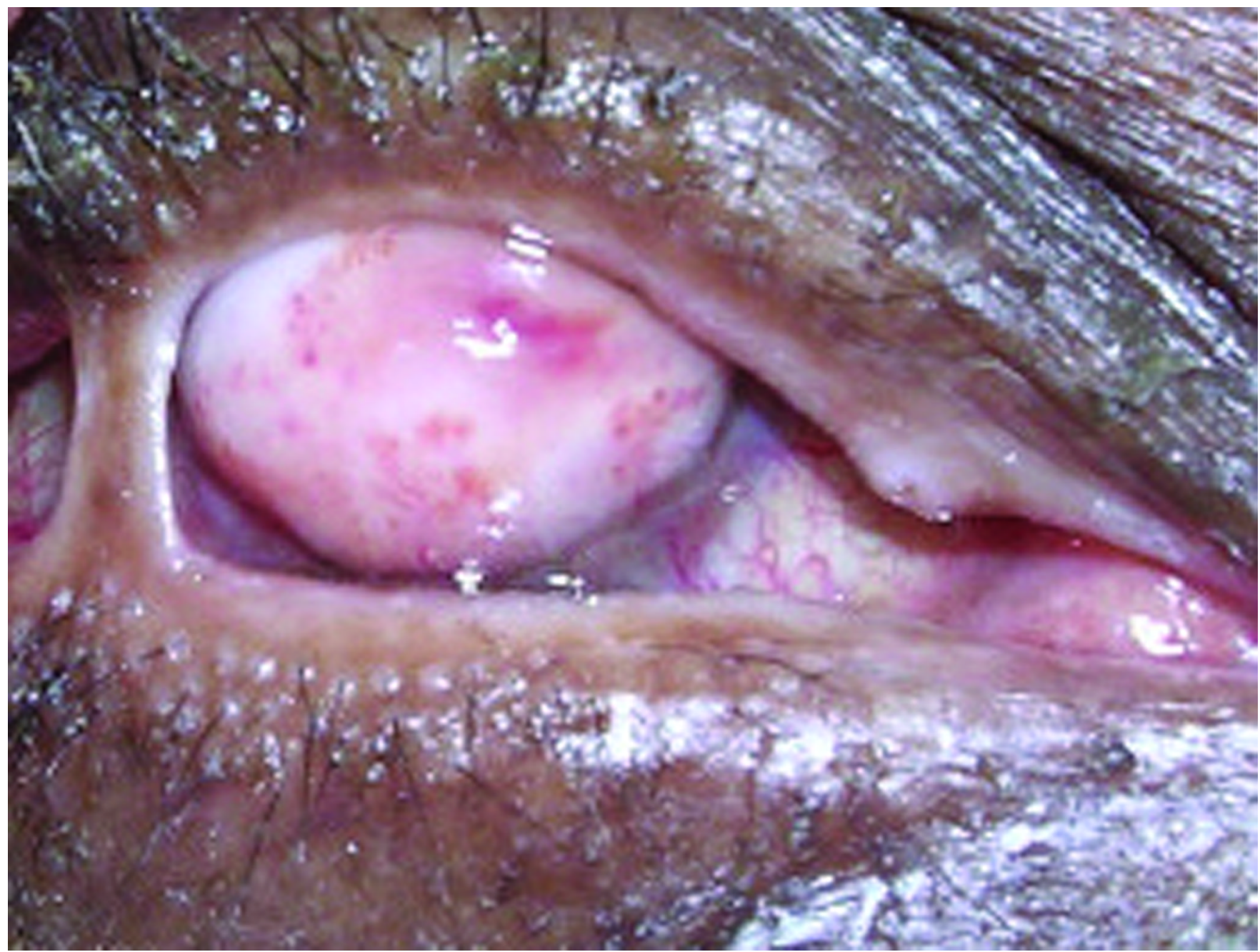

Figure 1.

Clinical appearance of right eye shows smooth, fleshy epibulbar mass. A tarsorraphy scar is also present. 


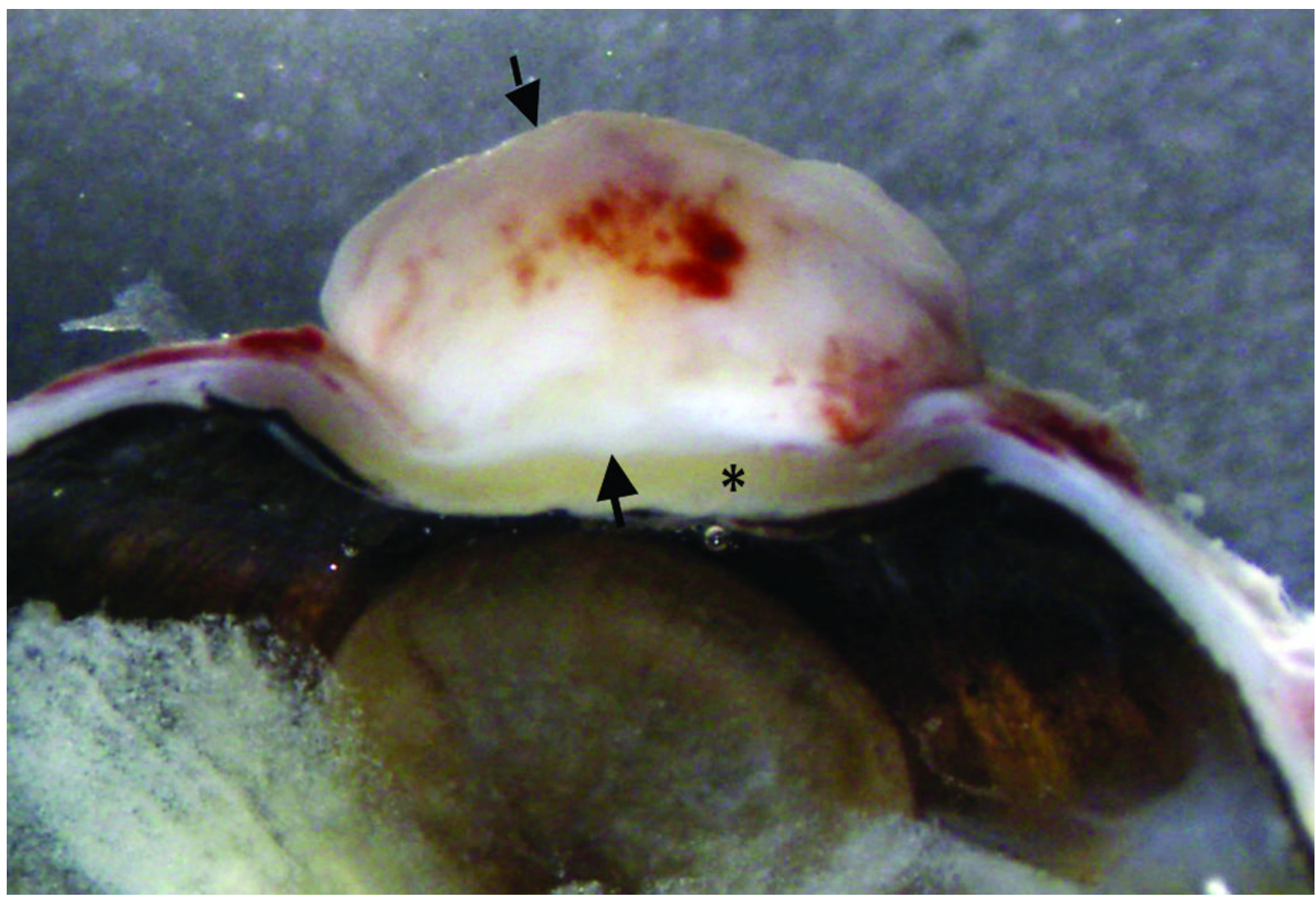

Figure 2.

The enucleated eye contains a white epibulbar mass. The cataractous lens and collapsed vitreous are also present. 


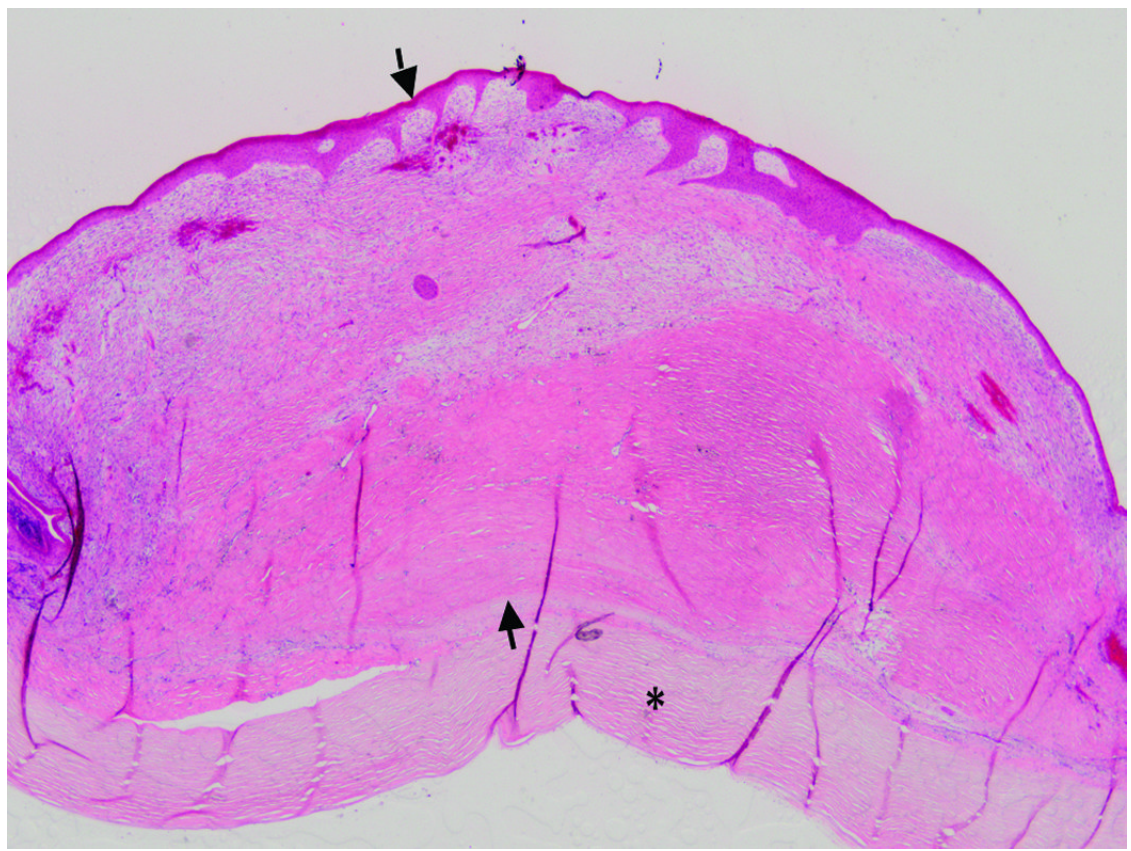

Figure 3.

The epibulbar mass is located between keratinized epithelium and Bowman's layer (between arrows). The underlying cornea $(*)$ is much thinner than the overlyingmass.(hematoxylin and eosin, $5 \times$ ) 


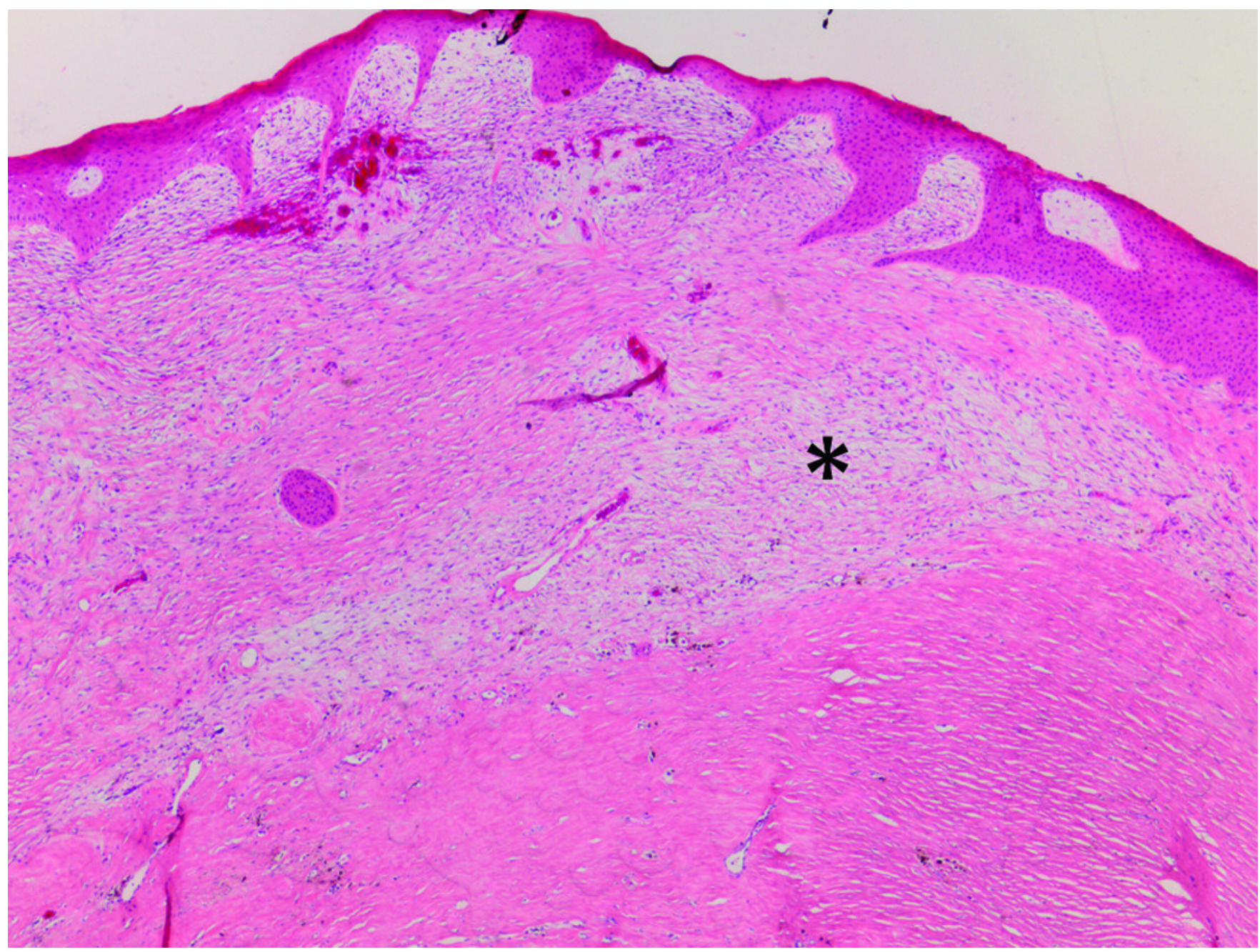




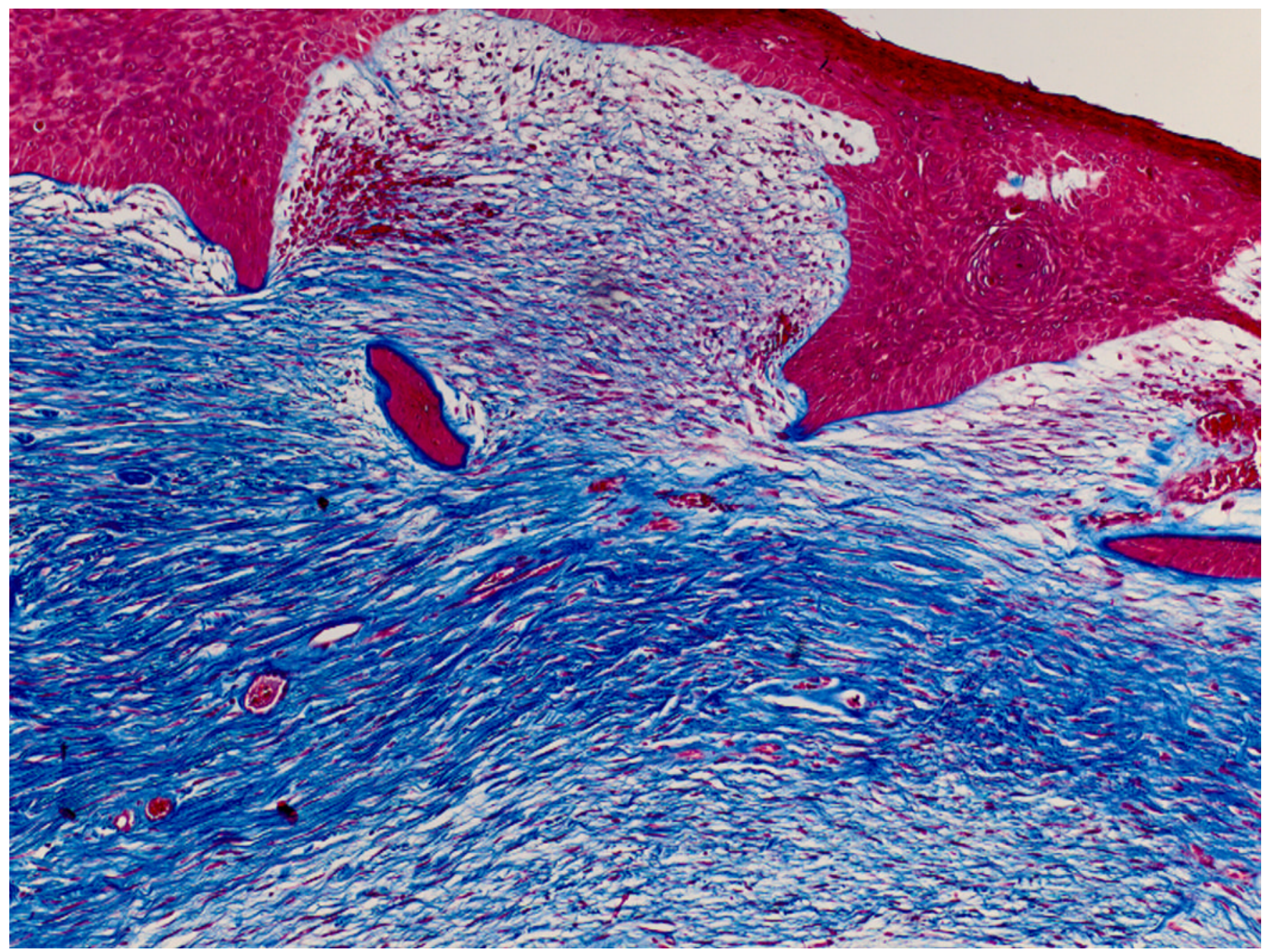

Figure 4.

A. The mass is composed of densly packed collagen and islands of more loosely coherent material $(*)$. B. The dense collagen is highlighted with a trichrome stain. (A. hematoxylin and eosin, 10x; B. Masson trichrome, 25x) 


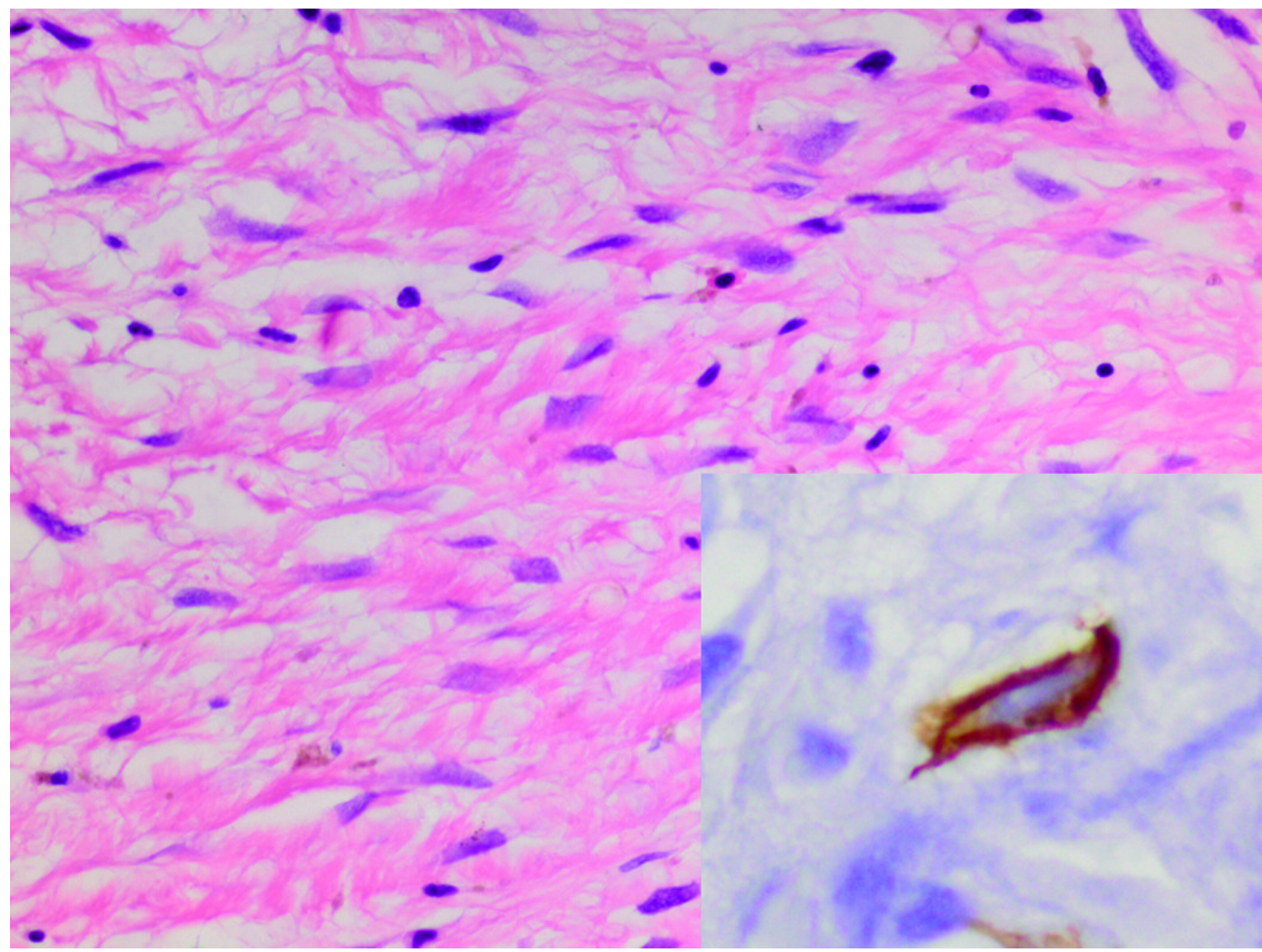

Figure 5.

There are spindle shaped cells with bland, fusiform nuclei in the loosely coherent portion of the epibulbar mass. (Inset) Scattered cells within the mass exhibit positive immunohistochemical staining for smooth muscle actin (SMA). (hematoxylin and eosin, $100 \times$ inset. peroxidase anti-peroxidase, 100×) 